\title{
Validation of the thin-walled composite box beams using FEM
}

\author{
Dr. P.M.Pawar ${ }^{1}$ K.M.Markad ${ }^{2}$ Kundan Mishra $^{3}$ \\ 1. Professor, Dept. of Civil Engineering, SVERI'S College of Engineering, Pandharpur, Maharashtra, India. \\ 2. Lecturer, Dept. of Mechanical Engineering, P.D.V.V.P. College of Engineering, Vilad Ghat, \\ Ahmednagar-414111,Maharashtra, India. \\ 3. Lecturer, Dept. of Mechanical Engineering, ZEAL Education society, Dnynganga College of Engineering, \\ Pune-411 046,Maharashtra, India.
}

\begin{abstract}
In present paper static analysis of thin walled composite beam with rectangular cell carried out. This beam modeled using 3D finite element method of thin walled composite beams. Different ply orientations are get selected for each face of the rectangular box beam. The numerical results obtained for thin-walled composite box beams under vertical load to investigate the effect of shear deformation is get analyzed with the finite element model. Thin walled composite box beam is modeled so as weight optimization achieved.
\end{abstract}

Keyword: Thin-walled box beam, FEM validation.

\section{Introduction}

Composites that forms heterogeneous structures which meet the requirements of specific design and function, imbued with desired properties which limit the scope for classification. However, this lapse is made up for, by the fact new types of composites are being innovated all the time, each with their own specific purpose like the filled, flake, particulate and laminar composites. Fibers or particles embedded in matrix of another material would be the best example of modern-day composite materials, which are mostly structural. Laminates are composite material where different layers of materials give them the specific character of a composite material having a specific function to perform. Fabrics have no matrix to fall back on, but in them, fibers of different compositions combine to give them a specific character. Reinforcing materials generally withstand maximum load and serve the desirable properties.

A composite laminate material consists of two or more distinct layers with specific structure assembled to achieve certain physical properties. The layers can be of different thicknesses, their inner fiber orientations may differ, and they may consist of different materials. A composite is constructed of layers, called lamina, that are bonded together. Each layer is composed of fibers and a polymer matrix material that is required to hold the fibers in position. The orientation angle of the fibers can change, which will, in effect, change the response of the beam. The orientation angles of all of the layers are known a layup. For example, $[0 / 90 / 90 / 0]$ is a composite layup with fibers in the top layer oriented at $0^{\circ}$, in the second layer at $90^{\circ}$, the third layer at $90^{\circ}$, and the bottom layer at $0^{\circ}$. This is also an example of a symmetric laminate because the layers are symmetric about the beam reference surface. It can be abbreviated as [090]s where the subscript refers to its symmetry.

\section{Present Theories and Practices}

A considerable research has been devoted in the past to improve the beam finite elements based on the classical Timoshenko-beam theory. Analysis of thick and thin walled beam with composite cross-section is presented in [1].The cross-section is discretized by cross-sectional elements and the compliance matrix is obtained numerically by assembling contributions of these elements; the rigid body mode of the cross-section are eliminated through appropriate constraints of the in-plane and out-of-plane warping parameters. Calculation of the stiffness of the beam element in this case is not simple and straightforward, especially in nonlinear analysis. Vlasov [2] developed the theory of thin walled elastic beam, which became the basis of modern theoretical models to analyze box girders. Magnucki [3] presented the comparative analysis of optimal thin-walled beam, and proposed a quality measure for thin-walled beams with various open cross sections.

Due to the advantages such as strength-to-weight ratio and flexibility specifications, composite laminated plates are widely used in industry. Many research works have been carried out to optimize the composite laminated plates to obtain a maximum stiffness or strength. Kim etai. [4] Investigated the optimal stacking sequence of a symmetrical laminated plate under in-plane loading to maximize the load bearing ability. Park [5] also investigated a laminated plate under in-plane loading and gave an optimal design method. 
Kam and Chang [6] used the multistart global optimization technique to optimize the ply orientation of a laminated plate for a maximum stiffness.

Over the past decade, a lot of research has been done on the optimization of composite structures. Most of these works were restricted to the plate type structures [7-12] because of the mathematical complexity involved in the analysis of other composite structures. However, in recent year, the commercially available finite element software makes it possible to optimize the complicated composite structures [13-15]. For example, Kere et al. [15] carried out the weight minimization of composite laminates by maximizing the strength for multiple loading conditions with number of layers and layer orientations as design variables. They considered an elastic composite beam with $\mathrm{Z}$ cross-section and used FE model to find the stresses. Weight savings are directly associated with a reduced fuel consumption and an increased payload, while the reduced manufacturing cost has an impact on the acquisition cost. Attempts for a combined cost/weight optimization have been done by Geiger and Dilts [16], Kassapoglou [17].

Finite element analysis has been useful and considered an accurate to develop 3D model simulating similar boundary and loading condition compared to the real-life problems. Several research papers have been published on finite element modeling of composite I-beam. Shell elements are commonly employed to model composite structures in two dimensions. Jung and Lee [18] studied composite I-beam using 2D shell element, 4-noded plate/shell element of MSC/NASTRAN. The slenderness ratio of the beam was kept within 20 for accurate results. Similarly, Barbero et al. [19] developed a finite element model using 8-node isoparametric laminate shell elements in ANSYS for refined Finite Element Analysis (FEA).

\section{Objective of the Study}

The primary objective of this research is to effectively conduct stress analysis of a thin walled Composite hollow rectangular beam. The study focuses on the procedure to calculate stresses and strains of each layer in laminates.

A 3D finite element model of thin walled composite box-beam is developed in ANSYS 12.0 to determine the stresses and strains. The model is also used to validate and compare the results from analytical expression. This study is intended to provide tools that ensure better designing options for Composite laminates.

\section{Need for the study}

Composites are being used widely as construction material in engineering industries because of their high strength to weight ratio, increased fatigue life and improved damage tolerant nature. Thin walled structures are integral parts of an aircraft. In many structures like rotor blades, wing spars antenna legs, submarine hulls, cooling shafts, medical tubing, connecting shafts, transmission poles, carbon fiber tail boom of helicopter and tube like structure in missiles and launch vehicles. etc. they can be modeled as one dimensional beam as the sectional dimensions are much small compared to the length. several nonclassical behaviors are exhibited by thin walled composite structures which include the effect of elastic coupling, transverse shear deformation and restrained tensional warping. These characteristics can be exploited to improve efficiency through proper modeling.

From the 3D model most of study of thin walled beam is done by converting 3D model into 1D model which will not give more detail about 3D behavior of beam as the detailed analysis not possible from 1D model. In this works the optimization of thin walled composite beam will be carried out using 3D model. The objective will be set from durability, manufacturability and minimum weight point of view.

\section{Numerical Example}

Throughout numerical examples, a tolerance of

$\varepsilon=10^{-3}$ and maximum allowable iterations of 20 (per load step) are used to check for convergence of nodal displacements in the Newton- Raphson iteration scheme. Ten quadratic elements with three nodes are used in the numerical computation. The initial solution vector is chosen to be the zero vectors, so that the first iteration solution corresponds to the linear solution. The results of the present analysis are given for both the linear and nonlinear case.

The stacking sequence for web laminate is different at each wall of beam. Left wall and right wall ply orientation is $[(0 / 90) \mathrm{s}] 2 \&[(0 / 90) 2] \mathrm{s}$ resp. Whereas for top and bottom flanges the stacking sequence is [0/Ø2/90]s \& [0/-Ø2/90]s respectively. The dimension of the top and bottom flanges can be seen in Fig 2 . The analysis is carried out assuming both plane stress $(\sigma s=0)$ and plane strain $(\varepsilon s=0)$ assumptions 
Fig. 2 A composite box beams under vertical loading condition.

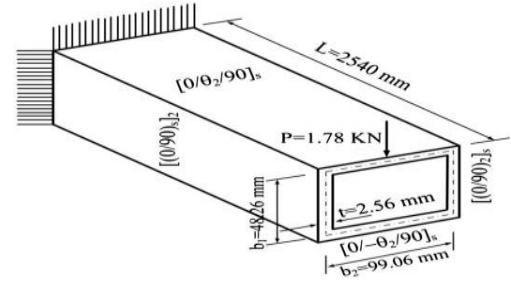

Table 1 properties of thin-walled box beam

\begin{tabular}{|l|c|}
\hline Property & value \\
\hline Width & $99.06 \mathrm{~mm}$ \\
Height & $48.26 \mathrm{~mm}$ \\
Thickness & $2.56 \mathrm{~mm}$ \\
Upper wall & {$\left[0 / \emptyset_{2} / 90\right] \mathrm{s}$} \\
Lower wall & {$\left[0 /-\emptyset_{2} / 90\right] \mathrm{s}$} \\
Left wall & {$[(0 / 90) \mathrm{s}] 2$} \\
Right wall & {$\left[(0 / 90)_{2}\right] \mathrm{s}$} \\
& \\
Material & $\mathrm{E} 1=146.79 \mathrm{GPa}$, \\
properties & $\mathrm{E} 2=10.3 \mathrm{GPa}$, \\
& $\mathrm{V} 12=.28$, \\
& $\mathrm{G} 12=\mathrm{G} 23=6.2 \mathrm{GPa}$, \\
& $\mathrm{GPa}$. \\
& \\
&
\end{tabular}

\section{Results Comparison Of The Thin-Walled Composite Box Beams:}

The stresses and strains in plies of sub-laminates of a laminated composite are calculated with the finite element model. In the present model analytical result by the stmple and Lee [20] is validated by using FEA. It is observed that analytical result is matches with FEA. The stresses in the plies are calculated in their respective principal coordinate axis i.e. stresses $\sigma 1, \sigma 2, \gamma 12$.

\begin{tabular}{|c|c|}
\hline Angle & Fem Result \\
\hline 0 & 0.015364 \\
\hline 15 & 0.19163 \\
\hline 30 & 0.313829 \\
\hline 45 & 0.184605 \\
\hline 60 & 0.134438 \\
\hline 75 & 0.036921 \\
\hline 90 & 0.014768 \\
\hline
\end{tabular}

Fig.3. variation of angle of twist w.r.t fiber angle change of a cantilever composite box beam under a 1.78 kN tip vertical load.Error! Not a valid link. 


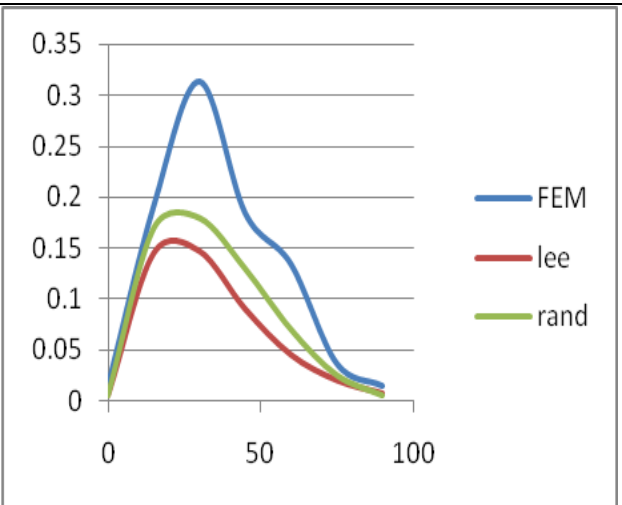

Fig. 4. Variation of vertical displacement w.r.t fiber angle change of a Cantilever composite box beam under a $1.78 \mathrm{kN}$ tip vertical load.

\begin{tabular}{|c|c|}
\hline Angle & Fem \\
\hline 0 & 0.015364 \\
\hline 15 & 0.19163 \\
\hline 30 & 0.313829 \\
\hline 45 & 0.184605 \\
\hline 60 & 0.134438 \\
\hline 75 & 0.036921 \\
\hline 90 & 0.014768 \\
\hline
\end{tabular}

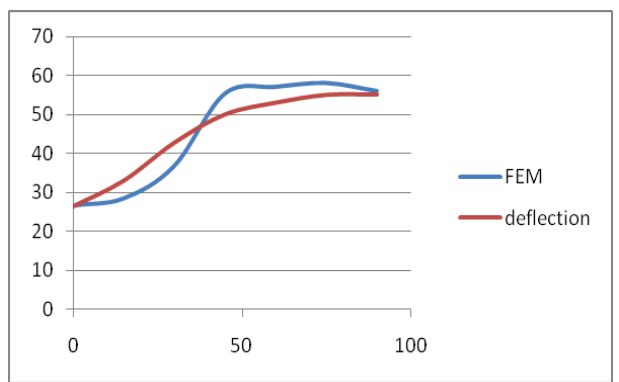

Fig. 5. Variation of the horizontal displacement with respect to fiber angle change of a cantilever composite box beam under a $1.78 \mathrm{kN}$ tip vertical load.

\begin{tabular}{|l|l|}
\hline Angle & FEM \\
\hline 0 & 0.05364 \\
\hline 15 & 0.19163 \\
\hline 30 & 0.313829 \\
\hline 45 & 0.184605 \\
\hline 60 & 0.134438 \\
\hline 75 & 0.036921 \\
\hline 90 & 0.014768 \\
\hline
\end{tabular}




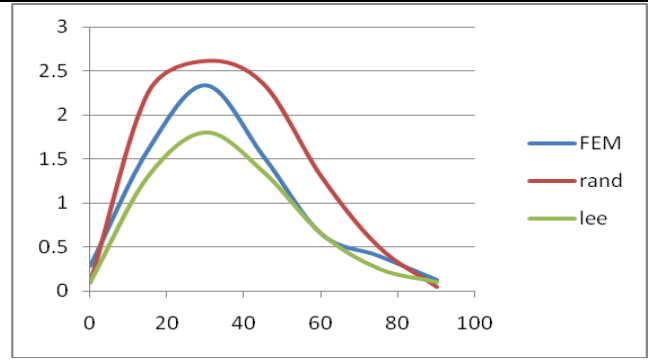

\section{Conclusions}

The results of finite element method were compared with analytical solution displacement-based onedimensional finite element model that accounts for the geometric nonlinearity is developed. Obtained numerical has been compared with the finite element method for the ply angle (fiber orientation), load parameter on axial-flexural-torsional response. The present model is found to be appropriate and efficient in analyzing geometrically nonlinear behavior of thin-walled composite beams.

\section{References}

[1] V. Giavotto, M. Borri, P. Mantegazza, G. Ghiringghellli, G.C.Maffioli, F. Mussi, Anisotropic beam theory and applications, comput. Struct.16 (403-413)1983.

[2] Vlasov VZ. Thin-walled elastic beams. Washigton, DC: National Science Foundation: 1961

[3] Magnucka-Blandzi E, Magnucki K. Optimal open cross section of thin walled beams. In:Loughlan J, editor. Thin walled structures, Advances in research, design and manufacturing technology. Proceeding of the fourth international conference on thin walled structures. Bristol and Philadelphia, Loughborough, UK: Institute of Physics pub;p 877-84,2004

[4] Kim CW, Hwang W,Park HC, Han KS.Stacking sequence optimization of laminated plates. Compos Struct 39:283-8.1997.

[5] Park WJ. An optimal design of simple symmetric laminates under the first ply failure criteria. J Compos Master 16:341-55:1982

[6] kam TY, Chang RR. Optimum layup of thick laminated composite plate for maximum stiffness, Eng Optimiz,19:273-49:1992.

[7] Adali S, Richter A, Verjenko VE. Optimization of shear-deformable laminated plates under buckling and strength criteria. Compos Struct;39(3-4):167-78,1997.

[8] Abu-Odeh AY, Jones HL. Optimumdesign of composite plate using respose surface method. ComposStruct;43(3)233-42,1998.

[9] Park JH, Hwang JH,Lee CS, Hwang W.Stacking sequence design of composite laminates for maximum strength using genetic algorithms.ComposStruct;52(2);217-31,2001.

[10] Sciuva MD, Gherlone M, Lomario D. multiconstrained optimization of laminated and sandwich plates using evolutionaryalgorithms and higher order plates theories.ComposStruct;59(1):149-54,2003.

[11] Narita Y, Hodgkinson JM. Layerwise optimization of maximizing the fundamental frequencies of point supported rectangular laminated composite plates.ComposStruct;69(2)127-35,2005.

[12] Farshi B, Herasati S. optimum wt.design of fiber composite plates in flexure based on a two level strategy.ComposStruct;73(4):495504,2006 .

[13] Muk A, Gurba W. genetic algorithms and finite element analysis in optimization of composite structures.ComposStruct;54(2-3):27581,2001

[14] Walker M, Smith RE.A technique for multi-objective optimization of composite structures usinggenetic algorithmsand finite element analysis.ComposStruct;62(1)123-8,2003.

[15] Kere P, Lyly M,Koski J. using multicriteria optimization of strength design of composite laminates.ComposStruct;62(3-4):329-33.2003.

[16] Geiger TS, DiltsDM.Automated design-to-cost; Integrating costing into the design decision. CAD computer aided design, 28(6-7):42338,1996 .

[17] Kassapoglou C. simultaneous cost and weight optimization of composite stiffened panels under compression and shear. Compos Part A: Applsci Manuf,28(5):419-35,1997

[18] Jung, S. N., and Lee, J. Y., "Closed-form analysis of thin-walled composite I-beams considering non-classical effects.”, Composite Structures Vol.60, 2003, pp. 9-17.

[19] Barbero, E. J., Lopez-Anido, R., and Davalos, J. F., "On the mechanics of thin-walled laminated composite beams." Journal of Composite Materials Vol.27 No.8, 1993, pp. 806-829.

[20] Stemple AD, Lee SW. Finite element model for composite beams undergoing large deflection with arbitrary cross sectional warping. Int J Numer Meth Eng 1989;28:2143-60. 